\title{
LEGITIMASI SENIMAN DAN KARYA SENI DI TAMAN BUDAYA JAMBI (TINJAUAN SOSIOLOGI SENI)
}

\section{ARTISM LEGITIMATION AND ART CREATURE IN JAMBI CULTURE PARK (REVIEW OF ART SOCIOLOGY)}

\author{
Defni Aulia, Mahdi Bahar, Indra Gunawan, M.Ardhi Muharam, Wahyu Pratomo, \\ Muhammad Alfath \\ Program Studi Seni, Drama, Tari, dan Musik Fakultas IImu Budaya Universitas Jambi
}

Naskah diterima: 9 Juni 2018; direvisi: 8 Mei 2019; disetujui: 20 Juni 2019

\begin{abstract}
Abstrak
Seniman dan karya seni bernuansa tradisional yang berada pada tatanan kode kultural masyarakat Jambi, adalah akumulasi modal kultural yang dilegitimasi pemerintah Provinsi Jambi untuk membentuk identifikasi distingtif sebagai citra kultural di luar batas teritorial Provinsi Jambi. Suatu mekanisme tindakan deviasi diferensial yang dilakukan oleh pemerintah dalam menjalankan otoritas otonom atau desentralisasi politik lokal, yang merupakan upaya untuk membedakan diri dari lajur Kebudayaan Minangkabau dan Melayu Islami yang selama ini sudah menyatu dan mendominasi dalam struktur sosial masyarakat Jambi.
\end{abstract}

Kata kunci: modal kultural, deviasi diferensial, legitimasi, dan konsekrasi habitus.

\section{Abstract}

Artists and traditional nuanced artworks that are in the order of the cultural code of the people of Jambi, are cultural capital accumulations that legitimized the government of Jambi Province to form distinctive identification as a cultural image outside the territorial boundary of Jambi Province. A mechanism of differential deviation action carried out by the government in carrying out autonomous authority or decentralization of local politics, which is an effort to distinguish themselves from the lane of Islamic Minangkabau and Malay Culture which has so far been united and dominated in the social structure of Jambi society.

Keywords: cultural capital, differential deviation, legitimacy, and habitus consecration.

\section{PENDAHULUAN}

Cipta karya kreator seni, baru dapat dilihat sebagai objek simbolis jika koneksinya diakui dan dikenali, artinya jika dilembagakan secara sosial sebagai karya seni dan diterima oleh para penikmat yang sanggup mengenali dan mau mengakuinya sebagai karya seni. ${ }^{1}$

Perihal ini merujuk pada keterlibatan "agen-agen" di luar produsen material (seniman) sebagai mediator yang ikut berperan dalam mengimposisi dan melegitimasi terkonsekrasinya karya seni, atau suatu

1 Pierre Bourdieu. The Field of Cultural Production. Randal Johnson (Ed.). (Columbia: Columbia University Press, 1993). 37. 
kondisi-kondisi sosial agen institusional yang membentuk mendefenisikan dan menghasilkan nilai suatu karya di dalam arena karya seni. ${ }^{2}$

$$
\text { Perspektif tersebut, jika }
$$
dikaitkan dengan produksi karya seni yang diproduksi dan diaktualkan kembali di dalam arena karya seni, tidak hanya melalui mekanisme kreatif produsen (seniman) atau ideologi kharismatik seniman dalam memproduksi bentuk karya seni, namun produsen dan produknya (seniman dan karyanya) tersebut terkait dalam sistem mekanisme relasional dengan mediator-mediator yang mengkosekrasinya.

Merujuk pada peran yang dimankan Taman Budaya Jambi ${ }^{3}$, sebagai perpanjangan tangan

\footnotetext{
${ }^{2}$ Pierre Bourdieu..., 1993. 37.

${ }^{3}$ Berdasarkan Surat Keputusan Mendikbud RI Nomor. 061/O/1992, tanggal 23 Januari 1992, Taman Budaya Provinsi Jambi secara resmi didirikan sebagai Unit Pelaksana Teknis Kebudayaan di Provinsi Jambi. Visi Taman Budaya Jambi: "Kesenian Sebagai Jatidiri Bangsa (Daerah)". Misi: (i) Menyerasikan, meningkatkan dan merelevansikan mutu seni dengan perkembanngan zaman.

Menyajikan apresiasi seni pertunjukan dan rupa. (iii) Meningkatkan intelektualitas wawasan seni yang menunjang kehidupan berkesenian. (iv) Menyebarluaskan informasi seni sebagai upaya peningkatan dan mengembangkan wawasan seni masyarakat. Dalam, Profil dan Program Taman Budaya Provinsi Jambi Tahun 2010. Dinas Kebudayaan Dan Pariwisata. (Data dalam bentuk Makalah elektronik). Diakses dari Herman, Divisi Publikasi dan Dokumentasi di Taman Budaya Jambi. Tanggal 10 Mei 2014.
}

pemerintah dan secara fungsional dipercaya mengelola aset seni budaya, sekaligus merupakan agen institusional dominan yang mempunyai otoritas secara independen ${ }^{4}$, dalam aktivitasnya mengakumulasi dan melegitimasi potensi suatu produk seni budaya di Provinsi Jambi, dipersepsi merupakan agen institusional yang dianalogikan sebagai suatu arena tempat dimana cipta karya diproduksi dan diestimasi menjadi karya seni, serta sebagai agen sosial yang berhubungan dengan otoritas kuasa dalam menentukan produsen (seniman), akumulasi, dan legitimasi modal kultural.

Persepsi arena dan agen ini menyatu dalam skema ruang tempat elaborasi produk, produsen, serta aktualisasinya, atau mengikuti pemikiran Lono Simatupang;

\begin{tabular}{lcr}
\multicolumn{1}{c}{ "sebagai } & motivator & dalam \\
meningkatkan & dinamika & dan \\
pengembangan & kehidupan budaya dan \\
seni, serta sebagai fasilitator dalam \\
menciptakan kondisi yang kondusif bagi
\end{tabular}

\footnotetext{
${ }^{4}$ Independent sebagai habitus arena karya seni dalam perspektif Bourdieu, adalah otoritas tindakan arena seni yang terdapat di dalam arena kekuasaan, yang secara otonom dapat menjalankan prinsip-prinsip hierarkisasi ekonomi dan politisnya, dalam pengertian dapat memutuskan logikanya sendiri sebagai suatu tindakan. Dalam, Pierre Bourdieu..., 1993. 3739.
} 
kehidupan dan keberlanjutan senibudaya".

Konkritnya, dalam konteks ideologis, Taman Budaya yang merupakan salah satu lembaga pemerintah dalam menangani aset seni budaya daerah -mengikuti pikiran Lono Simatupang- sudah seharusnya memainkan peran sebagai preservator budaya dan seni dalam mewadahi ekspresi-ekspresi budaya yang terpinggirkan, yang tidak atau belum dapat mengikuti arus perkembangan zaman, sehingga langkah preservasi yang dijalankan dapat menjaga alur kesejahteraan seni budaya, menumbuhkan kesadaran historis warga, serta menjaga ketersediaan sumber referensi budaya ketika dibutuhkan untuk pelbagai alasan dan tujuan. ${ }^{6}$

Peran tersebut, secara ideologis menunjukkan suatu kuasa simbolik agen institusional dalam mengimposisi dan melegitimasi citra kultural menjadi 'identitas daerah" ${ }^{7}$ dengan menjalankan 'hegemoni kultural'8 demi mencapai

\footnotetext{
Lono Simatupang. Pergelaran. (Yogyakarta, Jalasutra, 2013). 276.

${ }^{6}$ Lono Simatupang..., 2013. 276-277.

7 Identitas daerah disini merujuk pada identifikasi yang dikonstruksi berdasarkan perspektif administrasi (tata kelola) pemerintahan dalam kewenangan pengaturan pemerintahan. Dalam, Lono Simatupang..., 2013. 264.

8 Hegemoni cultural dalam hal ini merupakan blok histories yang menjalankan otoritas social dan kepemimpinan atas suatu
}

eksistensi dan identifikasi distingtif atas konstruksi budaya di luar batas teritorial.

Mengutip pikiran Bourdieu;

"bergerak menuju kemungkinankemungkinan yang lebih terbuka dan inovatif menuju kemungkinankemungkinan yang lebih aman dan mapan, atau bergerak menuju kemungkinankemungkinan yang paling baru di antara kemungkinan-kemungkinan yang sudah terbentuk secara sosial, atau bahkan menuju kemungkinan-kemungkinan yang harus diciptakan untuk pertama kalinya".

Karya seni yang dikonsekrasi sebagai salah satu bentuk seni budaya yang dilegitimasi berdasarkan ideologi preservasi, yang mekanisme aktualnya didasarkan atas relasi kuasa, merupakan hasil kerja bertahap Taman Budaya mengakumulasi modal kultural dalam bentuk seni pertunjukan yang secara signifikan bersifat dokumentatif dan merupakan aset dalam menjalankan proses transmisi kultural.

Mekanisme ini menunjukkan bahwa legitimasi karya seni yang dikelola oleh Taman Budaya sebagai preservator diwilayah kerja seni

kelas, disini, hegemoni melibatkan proses penciptaan makna, dimana representasi dan praktik dominant dan otoritatif diproduksi dan dipelihara. Dalam, Chris Barker. Cultural Studies; Teori dan Praktik. Terjemahan. Nurhadi. (Yogyakarta: Kreasi Wacana, 2004). 373.

${ }^{9}$ Pierre Bourdieu. The Field of Cultural Production..., 1993. 183. 
budaya, melaui otoritasnya secara mutlak berhak menentukan siapa produsen dalam melakukan proses encoding, dan dalam situasi bagaimana proses decoding diuraikan, dimana logika preservasi yang dikemas dalam produk artistik tersebut pada akhirnya diterima sebagai doxa ${ }^{10}$ terkonsekrasi.

Dari sini, -mengikuti pendapat Lono Simatupang- bahwa seharusnya peran-peran yang dapat dimainkan pemerintah dalam pengembangan kebudayaan dan kesenian memerlukan kebijakan yang tepat dan jelas, bahwa kebijakan kebudayaan tidak terbatas pada tugas dan wewenang instansi tertentu, misalnya Dinas Pariwisata, Seni dan Budaya. Kebudayaan seyogyanya diletakkan sebagai perspektif -bukan program, apalagi proyek- dan diterapkan pada semua sektor pemerintahan sehingga pelaksanaan peran-peran pemerintah dalam pengembangan kebudayaan dan kesenian seyogianya bersifat lintas sektoral. Sifat lintas sektoral tersebut tidak hanya berlaku pada tataran

${ }^{10}$ Doxa dalam pandangan Bourdieu, yaitu persepsi yang dihasilkan dari struktur sosial objektif, yang diterima begitu saja oleh suatu kondisi sosial tertentu sebagai sesuatu yang alami dan (seolah-olah) terbukti dengan sendirinya. Dalam, Pierre Bourdieu, Outline of a Theory of Practice. (Cambridge University Press, 1977). 164. konsolidasi program, namun juga dalam pendanaan dan pelaksanaan. ${ }^{11}$

Uraian yang tertulis diatas menunjukan, persepsi pola kerja Taman Budaya mengisyaratkan tentang bagaimana relasi kuasa melakukan ekspektasi terhadap ide-ide yang mesti dijalankan, tanpa mempertimbangkan mekanisme keberlanjutan. Di sini terlihat, bahwa dominasi Taman Budaya sangat kuat dalam mengimposisi struktur arena karya seni, imbasnya pada legitimasi produsen dan produk yang dikonsekrasi tertuju pada selera berdasarkan relasi kuasa.

Pada akhirnya, asumsi negatif muncul terhadap semua aktivitas kerja yang dilakukan Taman Budaya Jambi, bahwa kegiatan-kegiatan yang diprogramkan hanya bagian dari 'proyek' pelepasan anggaran pendapatan. Dari persepsi tersebut mengarahkan persepektif untuk ditindaklanjuti dalam proses analisis.

\section{Pembahasan}

\section{A. Seniman dan Karya Seni dalam} Struktur Arena Kultural

Cipta karya kreator seni berbasis tradisi budaya di Provinsi Jambi merupakan estimasi strategis atas

\footnotetext{
${ }^{11}$ Lono Simatupang..., 2013. 277
} 
akumulasi 'modal kultural'12 yang dimiliki pemerintah Provinsi Jambi agar tetap berada dalam arena percaturan budaya nasional, dan sebagai upaya membentuk 'identifikasi distingtif' ${ }^{13}$ atas citra aktivitas kultural masyarakat di luar teritorial Provinsi Jambi.

Cipta karya itu dilakukan merupakan tindakan 'deviasi diferensial ${ }^{14}$ pemerintah atas perspektif otoritas otonom (desentralisasi politik lokal) dalam membedakan diri dari lajur kebudayaan yang berada di lingkar teritorial perbatasan administrative (Minangkabau dan Melayu Islami) yang selama ini sudah menjadi 'pakaian'

${ }^{12}$ Bourdieu mendefinisikan modal kultural sebagai suatu bentuk pengetahuan, suatu kode internal atau akuisisi kognitif yang melengkapi agen sosial dengan empati terhadap (?), apresiasi terhadap (?), atau kompetensi didalam (?), pemilihan relasi-relasi dan artefak-artefak kultural. Dalam, Pierre Bourdieu. Distinction; A Social Critique of the Judgement of Taste. Translated. Richard Nice. (Cambridge: Harvard University Press, 1984). 2-3.

${ }^{13}$ Logika keberfungsian arena karya seni sebagai arena pergulatan, lebih mengandalkan strategi-strategi yang bertujuan memperoleh distingsi berarti bahwa hasil dari keberfungsian ini, apakah itu 'kreasi-kreasi' haute counture dimaksudkan untuk berfungsi secara berbeda, yaitu sebagai instrument distingsi, pertama antara fraksi-fraksi kelas, kemudian antara kelas-kelas. Dalam, Pierre Bourdieu..., 1993. 283.

14 Bourdieu mengatakan bahwa, subjek sosial, yang terklasifikasikan oleh klasifikasi mereka, membeda-bedakan diri melalui pembedaan yang mereka ciptakan, antara indah dan buruk, yang terhormat dan yang tidak sopan, dimana posisi mereka dalam klasifikasiklasifikasi objektif terekspresikan. Dalam, Pierre Bourdieu..., 1984. 6. masyarakat Jambi, ${ }^{15}$ serta merupakan "ide tentang perjuangan demi pengakuan sebagai dimensi fundamental kehidupan sosial, dimana perjuangan ini merupakan perjuangan atas akumulasi modal, -dan karenanya, mestilah ada suatu logika spesifik tentang akumulasi modal simbolik- atau modal yang dibangun berdasarkan pengetahuan dan pengenalan". 16

Tidak dapat disanggah, hampir seluruh struktur sosio-kultural masyarakat Provinsi Jambi, mempunyai keserupaan interperetatif dengan representasi budaya di lingkar teritorial (Minangkabau dan Melayu Islami), ${ }^{17}$ dalam pengertian, bahwa sistem kebudayaan yang tersebar di Pulau Sumatra, yang diidentifikasi dibawa oleh suku bangsa penjelajah dalam sirkulasi berdagang maupun mengkoloni, selalu beradaptasi dengan

15 Menurut William Marsden, penduduk Jambi adalah kaum pagan dan posisinya berada ditengah -menjorok ke selatan- di Pulau Sumatra, mengkonstruksi dua kebudayaan besar, yaitu; Kebudayaan Melayu dan Minangkabau. Dalam, William Marsden. Sejarah Sumatra. Terjemahan. Komunitas Bambu. (Depok: Komunitas Bambu, 2013 [1811]). 43-44.

16 Cheleen Mahar, "Pierre Bourdieu: Proyek Intelektual". dalam Richard Harker.., 2009. 22.

17 Ja'far Rasuh. Wawancara tanggal 3 Maret. di Taman Budaya Jambi. Lihat juga William Marsden..., 2013. 42-57. 
lingkungan di sekitar, ${ }^{18}$ persentuhan budaya pendatang dengan budaya yang telah ada sebelumnya menjadi perpaduan sinkretis $^{19}$ dan hybrid ${ }^{20}$ dalam korelasi bentuk maupun ideologis, ini menandakan sifat kebudayaan lebih lentur dan fleksibel dengan jangkauan wilayah yang tidak terbatas. $^{21}$

Skema tersebut menunjukkan persepsi kewajaran, jika melihat posisi teritorial Provinsi Jambi yang berada pada wilayah tengah pulau Sumatra yang berada diantara Provinsi Sumatra Barat, Pekan Baru, dan Palembang, mengkonstruksi budaya campuran, “walaupun Jambi 'bukan basis' peradaban Minangkabau dan Melayu Islami, tapi merupakan muara

18 T. Jacob. "Manusia Melayu Kuno", dalam kumpulan tulisan, Seminar Sejarah Melayu Kuno; Jambi, 7-8 Desembar 1992. (Pemda Tk. I. Jambi, 1992). 157.

19 Sinkretis menunjukkan persilangan budaya pada tataran spritual, dalam; Heddy Shri Ahimsa-Putra. Strukturalisme Levi-Strauss: Mitos dan Karya Sastra. Yogyakarta, Kepel Press, 2006. 337.

20 Hybrid dalam pandangan Bhabha, merupakan persilangan budaya yang terbentuk bersama perspektif peniruan (mimikri). $\mathrm{H}$. Bhabha. "Sign taken for Wonder" in H.L Gates $\mathrm{Jr}$ (ed.). (Chicago; University of Chicago Press), dikutip oleh, Muji Sutrisno. Muji Sutrisno. Hermeneutika Pascakolonial. (Yogyakarta: Kanisius, 2004). 28.

${ }^{21}$ Michel Foucault. The Order of Thing; An Archeology of the Human Science. (New York: Phanheon Book, 1970). ix. pertemuan dari asimilasi budaya-budaya yang bersentuhan tersebut". 22

Ketika sistem administratif pemerintahan terpusat (sebelum dan sesudah kemerdekaan) membagi wilayah teritorial menjadi provinsiprovinsi dengan sistem pemerintahan tersendiri $^{23}$ dalam mengelola dan mengaktualkan sumberdaya yang berada didalam area batas teritorial, egosentrisme antar wilayah adiministratif sering muncul untuk saling bersaing. ${ }^{24}$ Walaupun semangat Soempah Pemoeda sebagai dasar persatuan bersinergi dengan tumbuhnya semangat nasionalisme untuk

22 Hairul Saleh. Wawancara tanggal 15 Februari di Pulau Temiang, Kabupaten Tebo. Lihat juga, Jeffrey Hadler. Sengketa tiada Putus; Matriarkat, Reformisme Agama, dan Kolonialisme di Minangkabau. Terjemahan. Samsudin Berlian. (Jakarta: Freedom Institute, 2010). 7.

${ }^{23}$ Untuk lebih jelas mengenai perspektif pembagian daerah dan otonomi daerah, dari sistem pemerintahan kolonial sampai kemerdekaan, lihat, Joos Cot'e. "Mendekonstruksi Negara; Beberapa Perspektif Sejarah Tentang Desentralisasi dan Otonimi Daerah di Indonesia". Selanjutnya dalam, Jamil Gunawan, dkk (ed.). Desentrlisasi Globalisasi dan Demokrasi Lokal. (Jakarta: LP3ES, 2005). 22-48.

Tentang undang-undang desentralisasi tahun 1922 menciptakan provinsi-provinsi baru yang mempunyai otonomi administratif yang tersebar di Indonesia; lihat juga, Henk Schulte Nordholt dan Gerry van Klinken. Politik Lokal di Indonesia. (Leiden: KITLV Press, 2007). 1215.

24 Mudrajad Kuncoro. "Desentralisasi Sekedar Alat", dalam Jamil Gunawan, dkk (ed.)..., 2005. xxiv. 
membentuk identitas budaya nasional, ${ }^{25}$ tidak serta-merta mengubah konstruksi ideologis budaya yang sudah 'mapan' sebelumnya, ditambah dengan persaingan wilayah-wilayah administratif yang semakin kompetitif bersaing dalam memperebutkan simpati yang berimbas pada alokasi subsidi pemerintah pusat untuk bermacam tujuan dan preservasi aset wilayah teritorial. $^{26}$ Disini, karena bukan basis dari kebudayaan yang mapan, ${ }^{27}$ dan secara geografis berada di wilayah 'antara', ${ }^{28}$ maka konstruksi sosiokultural Provinsi Jambi terus berada dalam posisi ambang, ambivalensi, dan terus berada dalam bayang-bayang Budaya Minangkabau dan Melayu Islami.

\footnotetext{
25 Tentang semangat nasionalisme membentuk identitas budaya nasional, dapat ditelusuri dalam; Claire Holt. Melacak Jejak Perkembangan Seni di Indonesia. Terjemahan. R.M. Soedarsono. (Bandung: MSPI, 2000). 313.

${ }^{26}$ Henk Schulte Nordholt dan Gerry van Klinken. Politik Lokal di Indonesia. Leiden, KITLV Press, 2007. 25-27.

${ }^{27}$ Jambi bukan basis dari kebudayaan yang mapan disini, tidak ditelusuri berdasarkan sejarah peradaban melayu kuno yang bermigrasi ke pulau sumatera, namun dirujuk dari tulisan William Masrden (catatan colonial). Marsden mengatakan; penduduk Sumatra diklasifikasi dari Kerajaan Minagkabau dan Melayu; Achin, Batta, Rejang, dan Lampung. Dalam, William Marsden..., 2013 [1811]. 44.

28 Persepsi 'wilayah antara' menurut Bhabha merupakan bentuk relasi struktur lokalitas dan globalitas membentuk hibriditas imanen dalam struktur sosial yang ambivalensi. Dikutip oleh J. Supriyono, dalam Mudji Sutrisno..., 2004. 145.
}

Sejak beralihnya sistem pemerintahan sentralistik tahun 1998, dan diberlakukan undang-undang No.22/1999 ditahun 2000, mengenai desentralisasi dan demokratisasi lokal, ${ }^{29}$ bahwa pemerintahan tingkat II diberi otoritas otonom untuk mengelola sumber daya wilayah dan mengontrol mekanisme sistem pemerintahan tersendiri, persaingan di tingkat internal Provinsi Jambi menjadi semakin kompleks. Pemerintahan tingkat II (kabupaten) justru semakin gencar mempromosikan potensi-potensi unggulan yang dimilikinya, termasuk klaim atas cagar budaya dan 'autitensitas' produk (kultural) simbolis, yang secara langsung dapat diakses secara terbuka tanpa harus direkomendasi oleh pemerintahan pusat (Jambi).

Bourdieu berpendapat bahwa:

The network of objective relations between positions subtends and orients the strategies which the occupants of the different positions implement in their struggles to defend or improve their positions. $^{30}$

Pergulatan antar kebudayaan berbasis teritorial dalam mengimposisi

29 Problematisasi atas diberlakukannya sistem demokrasi lokal, dapat ditelusuri dalam; Irwan Abdullah. "Diversitas Budaya, Hak-hak Budaya Daerah, dan Politik Lokal di Indonesia", dalam Jamil Gunawan, dkk (ed.)..., 2005. 81 .

${ }^{30}$ Pierre Bourdieu..., 1993. 30. 
bentuk transmisi kultural simbolik, berimbas pada produk-produk artistik indigenous bernuansa tradisi kultural menempati posisi yang mendominasi dan terlegitimasi sebagai citra kultural atau sebagai identitas budaya, dan juga merupakan 'senjata' untuk melakukan pembedaan dan melakukan penekanan atas wilayah yang secara signifikan 'kurang' mengelola potensi aset local knowledge dalam kontinuitas membentuk citra 'autentisitas' daerah. Di sini, estimasi Provinsi Jambi yang kualitas sosio-kulturalnya lebih ditentukan oleh determinisme citra global dan demografi heterogen, ${ }^{31}$ yang secara kronologis mengalami degradasi atas modal kultural tradisional, tidak mampu bersaing dalam melegitimasi produk-produk artistik simbolik tersebut, namun secara signifikan diuntungkan dengan relasi kuasa atau lembaga yang dapat mengelola asset local knowledge yaitu Taman Budaya Jambi.

Perihal seperti ini dikatakan oleh Bourdieu sebagai 'fraksi terdominasi kelas dominan', bahwa;

Strategies which depend for their force and form on the position each agent

\footnotetext{
31 J. Supriyono. "Mencari Identitas Kultur Keindonesiaan”. Dalam Muji Sutrisno..., 2004. 139.
}

occupies in the power relations (rapports de force). ${ }^{32}$

Ketika negara merayakan serta mempertanyakan kembali aplikasi undang-undang tentang demokratisasi lokal yang dikontestasikan dalam bentuk seremonial festival-festival atau aktualisasi seni budaya lainnya, Provinsi Jambi berdasarkan otoritasnya mampu melakukan spekulasi dalam memproduksi dan merekonstruksi ulang produk indegenous, yang diidentifikasi memenuhi standar lokalitas, sekaligus memenuhi kualitas berbeda dari produk simbolis yang lain, yang sebelumnya sudah ada dalam arena produksi karya seni, baik distingsi (berbeda) atas bentuk artistik kultural simbolik yang dimiliki oleh provinsi tetangga, maupun perbedaan gaya dalam satu wilayah teritorial Provinsi Jambi.

$$
\begin{gathered}
\text { Lebih jauh } \\
\text { mengatakan: }
\end{gathered}
$$

Artistic field is the economic world reversed; that is, the fundamental law of this specific universe, that of disinterestedness, which estabilshes a negative correlation between temporal (notably financial) success and properly artistic value, is the inverse of the law of economic exchange. The artistic field is a universe of belief. Cultural production distinguishes itself from the production of the most common objects in that it must

\footnotetext{
${ }^{32}$ Pierre Bourdieu..., 1993. 30.
} 
produce not only the object in its materiality, but also the value of this object, that is, the recognition of artistic legitimacy. ${ }^{33}$

Tindakan spekulatif atas praktik yang dilakukan pemerintah Provinsi Jambi, atau produksi artistik untuk mencapai nilai konsekrasi dari suatu kondisi arena kultural menunjukan bahwa, pengaktualisasian praktik artistik, pada akhirnya tertuju pada stigma antisipasi atas citra kondisional Provinsi Jambi di dalam arena kultural yang dipersepsi berada pada posisi subordinat, dan berada pada 'ruang antara' dalam konstruksi idiom-idiom seni budaya sebagai modal kultural untuk melakukan legitimasi hierarki atas nilai artistik berdasarkan citra teritorial.

Hal ini secara signifikan dapat diestimasi bahwa posisi Provinsi Jambi saat ini berada pada wilayah terdominasi di arena 'pertarungan' budaya lokal dan nasional, dan secara strategis ingin memperebutkan konsekrasi hirarkis sebagai wilayah administratif yang otonom dalam arena artistik kultural.

Bourdieu menjelaskan, dalam mengimposisi arena:

\footnotetext{
${ }^{33}$ Pierre Bourdieu..., 1993. 164.
}

Every position taking is defined in relation to the space of possibles which is objectively realized as a problematic in the form of the actual or potential position takings corresponding to the different positions; and it receives its distinctive value from its negative relationship with the coexistent position takings to which it is objectively related and which determine it by delimiting it. ${ }^{34}$

Dalam hal ini, praktik-praktik artistic sebagai bentuk modal kultural yang dijadikan pertaruhan, merupakan strategi yang 'dipercaya' mampu bersaing dalam skema diferensial yang legitimit dari produk-produk artistik lainnya, yang sebelumnya sudah berada di dalam arena karya seni secara keseluruhan, serta praktik artistic tersebut "dianggap mampu menimbulkan efek distingtif sebagai produk artistik local knowledge yang dapat mengidentifikasikan sebagai citra ‘identitas kedaerahan’ Provinsi Jambi”.

\section{B. Cipta Karya Seni sebagai Citra Kultural}

Karya seni diproduksi dan ditempatkan dalam arena karya seni sebagai pertaruhan simbolis, adalah konstruksi ideologis atas 'semesta kepercayaan' yang ditanamkan Taman Budaya Jambi pada produk tersebut. Perihal ini berkaitan dengan strategi menentukan kembali posisi Provinsi

\footnotetext{
${ }^{34}$ Pierre Bourdieu..., 1993. 30.
} 
Jambi yang secara objektif berada pada posisi terdominasi di ranah kultural (lokal dan nasional), dan secara signifikan ingin mendisposisikan kembali kesejajaran citra kultural dengan wilayah lain sebagai penganut pola sistem pemerintah otonom.

Bourdieu menjelaskan:

The strategies of the agents and institutions that are engaged in literary struggles, that is, their position-takings (either specific, e.g. stylistic, or not, e.g. political or ethical), depend on the position they occupy in the structure of the field, that is, on the distribution of specific Simbolic capital, institutionalized or not ('celebrity' or recognition) and, though the mediation of the dispositions constituting their habitus (which are relatively autonomous with respect to their position). These strategies also depend on the state of the legitimate problematic, that is, the space of possibilities inherited from previous struggles, which tends to define the space of possible position-takings and thus orient the search for solutions and, as a result, the evolution of production. ${ }^{35}$

\section{Pengadaptasian kembali tradisi} budaya yang secara historis sudah 'punah', dan diinovasikan kembali menjadi karya seni dalam ruang dan bentuk yang berbeda, mengikuti pandangan Bourdieu, muncul berdasarkan 'periode retakan', dimana gramatika generatif mengenai bentuk-

\footnotetext{
${ }^{35}$ Pierre Bourdieu..., 1993, 183.
}

bentuk baru seni digandeng, dan tidak lagi meneruskan tradisi-tradisi estetis suatu masa atau sebuah lingkungan tertentu. $^{36}$

Disisi lain yang signifikan, bahwa karya seni yang ada dikonstruksi berdasarkan efek atas bias determinan dari suatu kondisi eksternal, yang dalam disposisi kulturalnya intensif bersaing secara kompetitif atas klaim autentisitas kultural di arena budaya (lokal dan nasional), yang secara objektif Provinsi Jambi di estimasi telah diposisikan berada pada ruang terdominasi.

Selain itu, 'ruang kemungkinan' lain munculnya aktivitas praktik rekonstruksi, juga berdasarkan tindaklanjut Taman Budaya atas polemik wacana revitalisasi seni budaya Jambi yang terus menjadi perbincangan pemerhati seni budaya di Provinsi Jambi $^{37}$ yang indikasi evaluatifnya dilihat dari aktivitas pelaku seni dalam merespon realitas sosio-kultural masyarakat Jambi melalui bentuk ekspresi artistik, bahwa aktivitas seni budaya Jambi "tidak lagi mempertimbangkan basis lokal, dan secara signifikan berpotensi

\footnotetext{
${ }^{36}$ Pierre Bourdieu..., 1993. 225.

37 Jumardi Putra. "Revitalisasi Budaya Jambi, Perlukah?”. (Koran Lokal: Jambi Expres, 14 Mei).
} 
menggantikan stuktur tradisi masa lalu dengan tradisi kekinian", ${ }^{38}$ atau stigma persepsi tersebut lebih mengarah pada hasil produk dalam logika common culture. $^{39}$

Taman Budaya Jambi sebagai salah satu lembaga pemerintah dalam mengola budaya memiliki otoritas kuasa legitimit di dalam arena politik lokal (fraksi terdominasi kelas dominan) secara signifikan berpeluang mewujudkan lebih banyak akumulasi praktik modal-modal kultural, dalam hal ini praktik produksi artistik di dalam 'ruang kemungkinan-kemungkinan'.

Prinsip ideologis ini, atau dominasi politis yang relasi hegemoninya dapat menentukan autentisitas terhadap hasil produk, kemudian dikemas dalam frame seniseni bernuansa lokal, sebagai antisipasi dari determinis pluralitas kondisi sosiokultural yang dipersepsi kehilangan posisi, dan terdominasi dari percaturan ranah kultural, dipergunakan untuk mengimposisi habitus arena, dialectic of

38 Azhar M.J. Wawancara tanggal 23 Februari, di Kediamannya, Kota Jambi.

${ }^{39}$ Common culture yaitu suatu budaya yang dimiliki bersama bersifat massif, dan suatu budaya yang rendah, vulgar dan tidak sopan, dan jelas membutuhkan beberapa arahan dan petunjuk untuk menjadikannya tinggi dan sopan. Dalam, Mike Featherstones, Posmodernisme dan Budaya Konsumen. Terjemahan. Misbah Zulfa Elizabeth. (Yogyakarta, Pustaka pelajar, 2008). 307. the internalization of externality and the externalization of internality, ${ }^{40}$ untuk mengimposisi "Economic or political interest in the sense of interest in success and in the related economic or political profit, constitute one of the bases for evaluating the producers and their products", 41 dan sekaligus dijadikan model untuk menstrukturkan kembali struktur arena dalam merekonstruksi ulang disposisi Provinsi Jambi beserta autentisitas produk local knowledge di dalam arena karya seni skala luas dan skala terbatas, yang image kultural sebelumnya sudah terbangun atas konstruksi budaya serapan dari Budaya Minangkabau dan Melayu Islami.

Seperti yang dikatakan Bourdieu:

The field of power is a field of latent, potential forces which play upon any particle which may venture into it, but it is also a battlefield which can be seen as a game. In this game, the trump cards are the habitus, that is to say, the acquirements, the embodied, assimilated properties, and capital as such, that is, the inherited assets which define the possibilities inherent in the field. These trump cards determine not only the sryle

${ }^{40}$ Pierre Bourdieu. Outline of a Theory of Practice. (London: Cambridge University Press, 1977). 72.

${ }^{41}$ Pierre Bourdieu..., 1993. 46. 
of play, but also the success or failure in the game. ${ }^{42}$

Karya seni yang di produksi sebagai modal yang dipertaruhkan dalam pertarungan merebut konsekrasi yang ditawarkan Provinsi Jambi untuk dilegitimasi secara terbuka di arena karya seni skala luas, adalah modal simbolis yang mengacu pada derajat akumulasi yang dibangun atas dialektika pengetahuan dan berada dalam kompetensi kultural. Perihal ini dimengerti bahwa, karya seni yang diproduksi, secara historis terbentuk berdasarkan fungsi ekonomisnya, dan berdasarkan fungsi estetisnya, merupakan dialektika atas kompetensi yang derajat akumulasi modal simboliknya diperkirakan dapat ditempatkan dan dipertaruhkan di dalam arena karya seni.

Persepsi ini menunjukan bahwa, aktualisasi karya seni yang diproduksi merupakan skema hegemoni dari sistem 'ekonomi terbalik', atau suatu perspektif yang ditanamkan atas orientasi nilai ekonomis bukan pada laba material, namun lebih kepada apresiasi simbolis, yaitu konsekrasi agen dan produk artistik sebagai pengakuan eksistensi yang legitimit

\footnotetext{
${ }^{42}$ Pierre Bourdieu..., 1993, 150.
}

didalam arena karya seni. Perihal ini didasari atas praktik evaluasi dari manifestasi 'ruang kemungkinan' 43 dan disposisi agen $^{44}$ untuk melegitimasi produk artistik dengan cara hegemonik $^{45}$ dalam mencapai konsekrasi hierarkis.

Bourdieu mengatakan, bahwa pertarungan di dalam arena adalah memperebutkan hak untuk mengimposisi prinsip dominasi yang dominan, atau membalikan citra produk kanonis yang terkonsekrasi menjadi bentuk relatif, dan melegitimasi produk yang mempunyai nilai distingtif untuk menempati posisi terkonsekrasi di arena karya seni berdasarkan semesta kepercayaan publik kultural dan ruang kemungkinan spekulatif.

${ }^{43}$ Ruang kemungkinan merupakan skema problematic dalam bentuk pengambilan posisi aktual dan potensial sesuai dengan beragam posisi yang ada. Dalam, Pierre Bourdieu...., 1993. 30.

44 Bourdieu mendefinisikan agen sebagai individu (atau kolektif) yang melakukan praktik berdasarkan sistem habitus atau dialektika internalisasi eksternalitas dan eksternalisasi internalitas, yang berbeda dari perspektif agensi yang lebih bersifat subjektif dan eksistensialis. Dalam, Pierre Bourdieu. Outline of a Theory of Practice. (London: Cambridge University Press, 1977). 72-78.

45 Dalam hal ini, Hegemonik dipahami sebagai suatu ideologi rekonstruksi demokratik dari bangsa atau suatu komunal diseputar inti kelas yang baru. Dalam, Ernesto Laclau dan Chantal Mauffe. Hegemoni dan strtegi sosialis. Terjemahan, Eko Prasetyo Darmawan. (Yogyakarta: Resist Book, 2008). 89. 
Skema tersebut, jika didekatkan dengan pandangan Bourdieu bahwa:

...ruang kemungkinan-kemungkinan yang tersedia dari analisis pembacaan arena mengorientasikan kerja-kerja artistik dan kreatif dari para agen di dalam ranah kreativitas kultural, dan mendefinisikan persoalan serta tantangan agar mereka merumuskan strategi-strategi tertentu untuk dapat ikut dalam permainan dan memenangkan pertarungan. ${ }^{46}$

Perihal tersebut dimengerti, bahwa strategi imposisi pemerintah Provinsi Jambi mengaktualkan kembali karya seni dalam bentuk 'baru', yang terbalut dalam logika preservasi dan transmisi, bertujuan melegitimasi secara formal karya simbolis yang terlepas dari dua kutub kebudayaan Minangkabau dan Melayu Islami, dalam hal ini Provinsi Jambi mencoba mengkonsekrasi identitas kulturalnya melalui karya seni di dalam arena karya seni, sebagai provinsi yang otonom dalam perspektif kulturalnya.

Sependapat dengan Barker, ${ }^{47}$ bahwa mekanisme inovatif bukan saja perihal kualitas tindakan, melainkan suatu penilaian restropektif yang dilakukan terhadap bentuk, dan hasil dari tindakan yang tercipta dari relasi

\footnotetext{
${ }^{46}$ Pierre Bourdieu..., 1993, 176.

${ }^{47}$ Chris Barker. Cultural Studies; Teori dan Praktik. Terjemahan. Nurhadi. (Yogyakarta: Kreasi Wacana, 2004). 194-195.
}

dengan tindakan lain dalam dinamika kultural historis tertentu.

Perihal tersebut dimengerti bahwa, praktik inovasi juga mempertanyakan tentang kinerja berdasarkan atas konteksnya, dan tindakan inovatif merupakan konsekuensi dari diskursus yang terbentuk dalam suatu ranah kehidupan kultural yang beralih ke ranah lain, serta perubahan inovatif dimungkinkan karena realitas interdiskursif dan diskursus yang membangun masyarakat bersifat kontradiktif.

Wacana kultural dalam tindakan inovasi modal simbolis yang dibentuk pada tatanan teritorial, mau tidak mau berdialektika dengan skema integrasi sosial yang imanen dan termanifestasi dalam identitas kultural. Sistem otonomi wilayah teritorial merupakan konsep politis yang mengacu pada aparatus administratif yang dipercaya memiliki kedaulatan atas arena tertentu dalam membentuk identifikasi imajinatif terhadap diskursus simbolis, ${ }^{48}$ dalam pengertian, bahwa sistem otonomi tidak hanya formasi politis, melainkan sistem representasi kultural yang identitas teritorialnya harus terus menerus

\footnotetext{
${ }^{48}$ Chris Barker..., 2004. 207-208.
} 
direproduksi sebagai tindakan diskursif

dalam imajinasi komunitas terbayang, ${ }^{49}$

dan the representation which individuals and groups inevitably project through their practices and properties is an integral part of social reality. A class is defined as much by its being-perceived as by its being, by its consumption, as much as by its position in the relations of production. $^{50}$

$$
\text { Pada akhirnya kesimpulan }
$$
sementara atas persepsi tindakan pengambilan posisi dalam arena kultural yang dilakukan pemerintah Provinsi Jambi melalui perpanjangan tangan Taman Budaya Jambi, mengarah pada suatu strategi dalam membentuk identifikasi distingtif sebagai citra kultural yang otonom atas dasar skema integratif suatu imajinasi komunitas terbayang berdasarkan sistem teritorialisasi dengan menjalankan 'politik kultural', 51 atau

\footnotetext{
${ }^{49}$ Anderson beranggapan bahwa imagined communities dikatakan terbayang adalah karena para anggotanya dari suatu komunal terkecil sekalipun tidak akan pernah mengenal, bertemu, dan bertukar kabar sebagian besar anggota yang lain, namun berdaulat membentuk integrasi social dan identitas nasional. Dalam, Benedict Anderson. Imagined Communities. Terjemahan. Omi Intan Naomi. (Yogyakarta: Insist Press, 2001). 8-9.

${ }^{50}$ Pierre Bourdieu..., 1984. 483.

51 Secara luas, Politik Kultural terkait dengan (i) kekuasaan untuk menamai; (ii) kekuasaan untuk merepresentasikan pendapat
}

serangkaian perjuangan kolektif yang terorganisasi untuk mendeskripsikan ulang suatu tatanan sosial demi meraih nilai-nilai secara spesifik.

\section{SIMPULAN}

Praktik artistik bernuansa lokal, mengikuti pemikiran Bourdieu, baru dapat dilihat sebagai objek simbolis jika koneksinya diakui dan dikenali, artinya jika dilembagakan secara sosial sebagai karya seni dan diterima oleh para penikmat yang sanggup mengenali dan mau mengakuinya sebagai karya seni. $^{52}$ Perihal ini merujuk pada keterlibatan agen-agen di luar produsen material (seniman) sebagai mediator yang ikut berperan dalam mengimposisi dan melegitimasi terkonsekrasinya karya seni, atau suatu kondisi-kondisi sosial agen institusional yang membentuk mendefenisikan dan menghasilkan nilai suatu karya di dalam arena karya seni. $^{53}$

Perspektif tersebut, jika dikaitkan dengan praktik artistik yang diproduksi dan diaktualkan kembali di dalam arena karya seni, tidak hanya

umum; (iii) kekuasaan untuk menciptakan 'versi resmi'; (iv) kekuasaan untuk merepresentasikan dunia social yang legitim]. Dalam, Chris Barker..., 2004. 372.

\footnotetext{
${ }^{52}$ Pierre Bourdieu..., 1993. 37.

${ }^{53}$ Pierre Bourdieu..., 1993. 37.
} 
melalui mekanisme kreatif produsen (seniman) atau sebagai ideologi kharismatik seniman dalam memproduksi bentuk karya seni, namun produsen dan produknya (seniman dan karyanya) tersebut terkait dalam sistem mekanisme relasional dengan mediator-mediator yang mengkosekrasinya.

Perihal ini menunjukkan peran Taman Budaya Jambi $^{54}$ sebagai perpanjangan tangan pemerintah, yang secara fungsional dipercaya mengelola aset seni budaya sekaligus merupakan agen institusional dominan yang mempunyai otoritas secara independen $^{55}$ dalam aktivitasnya

\footnotetext{
${ }^{54}$ Berdasarkan Surat Keputusan Mendikbud RI Nomor. 061/O/1992, tanggal 23 Januari 1992, Taman Budaya Provinsi Jambi secara resmi didirikan sebagai Unit Pelaksana Teknis Kebudayaan di Provinsi Jambi. Visi Taman Budaya Jambi: "Kesenian Sebagai Jatidiri Bangsa (Daerah)". Misi: (i) Menyerasikan, meningkatkan dan merelevansikan mutu seni dengan perkembanngan zaman. (ii) Menyajikan apresiasi seni pertunjukan dan rupa. (iii) Meningkatkan intelektualitas wawasan seni yang menunjang kehidupan berkesenian. (iv) Menyebarluaskan informasi seni sebagai upaya peningkatan dan mengembangkan wawasan seni masyarakat. Dalam, Profil dan Program Taman Budaya Provinsi Jambi Tahun 2010. Dinas Kebudayaan Dan Pariwisata. (Data dalam bentuk Makalah elektronik). Diakses dari Herman, Divisi Publikasi dan Dokumentasi di Taman Budaya Jambi. Tanggal 10 Mei.

${ }^{55}$ Independent sebagai habitus arena karya seni dalam perspektif Bourdieu, adalah otoritas tindakan arena seni yang terdapat di dalam arena kekuasaan, yang secara otonom dapat menjalankan prinsip-prinsip hierarkisasi ekonomi dan politisnya, dalam pengertian dapat
}

mengakumulasi dan melegitimasi potensi suatu produk seni budaya di Provinsi Jambi.

Taman Budaya dalam konteks ini dipersepsi merupakan agen institusional yang dianalogikan sebagai suatu arena tempat dimana praktik artstik diproduksi dan diestimasi menjadi karya seni, serta sebagai agen sosial yang berhubungan dengan otoritas kuasa dalam menentukan produsen (seniman), akumulasi, dan legitimasi modal kultural. Persepsi arena dan agen ini menyatu dalam skema ruang tempat elaborasi produk, produsen, serta aktualisasinya, atau mengikuti pemikiran Lono Simatupang, "sebagai motivator dalam meningkatkan dinamika dan pengembangan kehidupan budaya dan seni, serta sebagai fasilitator dalam menciptakan kondisi yang kondusif bagi kehidupan dan keberlanjutan seni-budaya". 56

Konkritnya, dalam konteks ideologis, Taman Budaya yang merupakan salah satu lembaga pemerintah dalam menangani aset seni budaya daerah -mengikuti pikiran Lono Simatupang- sudah seharusnya

memutuskan logikanya sendiri sebagai suatu tindakan. Dalam, Pierre Bourdieu..., 1993. 3739.

56 Lono Simatupang. Pergelaran. Yogyakarta, Jalasutra, 2013. 276. 
memainkan peran sebagai preservator budaya dan seni dalam mewadahi ekspresi-ekspresi budaya yang terpinggirkan, yang tidak atau belum dapat mengikuti arus perkembangan zaman, sehingga langkah preservasi yang dijalankan dapat menjaga alur kesejahteraan seni budaya, menumbuhkan kesadaran historis warga, serta menjaga ketersediaan sumber referensi budaya ketika dibutuhkan untuk pelbagai alasan dan tujuan. ${ }^{57}$

Peran tersebut, secara ideologis menunjukkan suatu kuasa simbolik agen institusional dalam mengimposisi dan melegitimasi citra kultural menjadi 'identitas daerah" ${ }^{\text {58 dengan }}$ menjalankan 'hegemoni kultural'59 demi mencapai eksistensi dan identifikasi distingtif atas konstruksi budaya di luar batas teritorial.

Mengutip pikiran Bourdieu,

${ }^{57}$ Lono Simatupang..., 2013. 276-277.

58 Identitas daerah disini merujuk pada identifikasi yang dikonstruksi berdasarkan perspektif administrasi (tata kelola) pemerintahan dalam kewenangan pengaturan pemerintahan. Dalam, Lono Simatupang..., 2013. 264.

59 Hegemoni cultural dalam hal ini merupakan blok histories yang menjalankan otoritas social dan kepemimpinan atas suatu kelas, disini, hegemoni melibatkan proses penciptaan makna, dimana representasi dan praktik dominant dan otoritatif diproduksi dan dipelihara. Dalam, Chris Barker..., 2004. 373.
"Towards more open and more innovative possibilities, or towards the most secure and established possibilities, towards the newest possibilities among those which are already socially constituted, or even towards possibilities that must be created for the first time". ${ }^{60}$

Praktik-praktik artistic yang dikonsekrasi sebagai salah satu bentuk seni budaya yang dilegitimasi berdasarkan ideologi preservasi, yang mekanisme aktualnya didasarkan atas relasi kuasa, merupakan hasil kerja bertahap Taman Budaya mengakumulasi modal kultural dalam bentuk seni pertunjukan yang secara signifikan bersifat dokumentatif dan merupakan aset dalam menjalankan proses transmisi kultural.

Jafar Rasuh mengungkapkan, "bahwa setiap tahunnya pemerintah daerah telah menganggarkan dana kepada Taman Budaya untuk melakukan penelitian, pengarsipan, dan pergelaran seni budaya sebagai aset wilayah Provinsi Jambi". ${ }^{61}$ Melalui kepercayaan tersebut, "Taman Budaya membentuk tim untuk melakukan observasi dan reka-ulang tradisi budaya di kabupaten-kabupaten. ${ }^{62}$

Hasil observasi dan reka-ulang tradisi budaya yang dilakukan Taman Budaya tersebut, kemudian

60 Dalam, Pierre Bourdieu. The Field of Cultural Production..., 1993. 183.

${ }^{61}$ Ja'far Rasuh. Wawancara tanggal 10 Mei, di Taman Budaya Jambi.

62 Azhar M.J. Wawancara tanggal 23 Februari, di Kediamannya, Kota Jambi. 
dipercayakan kepada Azhar MJ sebagai eksekutor dalam mengelaborasi objek material menjadi ekspresi artistik, yang selanjutnya dipergelarkan pada eventevent pertunjukan, ${ }^{63}$ sebagai mekanisme atas eksistensi distingtif dari perspektif global interconnectedness yang terkodifikasi dalam citra kultural. ${ }^{64}$

Mekanisme aktualisasi praktik artistik yang dilakukan Taman Budaya tersebut dipersepsi sebagai kerangka preservasi yang dijalankan melalui konsep politik kultural. Kerangka ini menunjukkan bahwa legitimasi karya seni, diantaranya, the monopoly of literary legitimacy, i.e., illter alia, the monopoly of the power to say with authority who are authorized to call themselves, writers; or, to put it another way, it is the monopoly of the power to consecrate producers or products. ${ }^{65} \mathrm{Hal}$ ini dimengerti bahwa, Taman Budaya sebagai preservator diwilayah kerja seni budaya, melaui otoritasnya secara mutlak berhak menentukan siapa produsen dalam melakukan proses encoding, dan dalam situasi bagaimana proses decoding

63 Ja'far Rasuh. Wawancara tanggal 10 Mei, di Taman Budaya Jambi.

${ }^{64}$ Pierre Bourdieu..., 2011. 102-108.

${ }^{65}$ Pierre Bourdieu..., 1993. 43. diuraikan, dimana logika preservasi yang dikemas dalam produk artistik tersebut pada akhirnya diterima sebagai doxa ${ }^{66}$ terkonsekrasi.

\section{Afirmasi Taman Budaya}

sebagai lembaga institusional yang menjalankan politik kultural dalam basis wilayah teritorial, yang merupakan praktik diskursus dalam konteks 'governmentalitas', 67 pada akhirnya secara positif dipahami sebagai upaya membentuk integrasi dan 'modal sosial'"68 dalam skema proses transimisi dan preservasi, serta menjaga eksistensi pemerintah

${ }^{66}$ Doxa dalam pandangan Bourdieu, yaitu persepsi yang dihasilkan dari struktur sosial objektif, yang diterima begitu saja oleh suatu kondisi sosial tertentu sebagai sesuatu yang alami dan (seolah-olah) terbukti dengan sendirinya. Dalam, Pierre Bourdieu, Outline of a Theory of Practice. (Cambridge University Press, 1977). 164.

67 Foucoult menjelaskan bahwa, governmentalitas merupakan suatu usaha yang terbentuk oleh institusi, prosedur, analisis dan refleksi, kalkulasi dan taktik yang memungkinkan dijalankannya bentuk kekuasaan yang spesifik, yang targetnya adalah masyarakat, dengan bentuk pengetahuan prinsipnya adalah ekonomi politik. Dalam, Chris Barker..., 2004. 390.

${ }^{68}$ Modal sosial merupakan sumber daya, aktual, yang berkumpul pada agen sosial karena memiliki jaringan tahan lama berupa hubungan timbal balik perkenalan dan pengakuan yang sedikit banyak terinstitusionalisasikan (mediasi komunikasi sosial), serta merupakan bagian dari organisasi sosial, (seperti kepercayaan, norma, dan jaringan), dalam memperbaiki efisiensi masyarakat dengan memfasilitasi tindakan terkoordinasi. Pierre Bourdieu dan Wancquant, L. An Invitation to Reflexive Sociology. Dalam John Field, Social Capital. (London, Routledge, Taylor \& Francis Group, 2008). 17. 
teritorial atas pergaulan politik kebudayaan skala luas. Dalam hal ini diestimasi secara signifikan, bahwa Taman Budaya dalam melakukan suatu 'kekerasan simbolik' ${ }^{69}$ dan mensubordinasi produsen lain di luar arena Taman Budaya yang juga pelaku di wilayah seni budaya, dipersepsi sebagai aktualisasi positif dalam otoritas mengkonstruksi suatu tatanan teritorial yang distingtif untuk mengindentifikasi citra identitas kedaerahan, yang secara intensif harus terus diaktualkan demi eksistensi strategis atas pergaulan budaya skala luas. Ini menunjukan bahwa, orientasi dari kerja-kerja artistik dan kreatif para agen di dalamnya hanya untuk mendefinisikan persoalan dan tantangan agar mereka merumuskan strategi-strategi tertentu untuk dapat ikut dalam permainan dan memenangkan pertarungan. ${ }^{70}$

Namun, pada sisi lain Bourdieu menerangkan:

69 Legitimasi atas 'kekuasaan simbolik' atau kekuasaan untuk membentuk fakta yang diterima sebagai 'hal benar' dengan cara menyatakannya, dan pelaksanaan kekuasaan tersebut disebut sebagai 'kekerasan simbolik', atau kekuasaan untuk memaksakan instrumeninstrumen pengetahuan dan ekspresi realitas sosial. Pierre Bourdieu, dalam Richard Harker..., 2009, 120.

${ }^{70}$ Pierre Bourdieu..., 1993. 176.
Because the fields of cultural production are universes of belief which can only function in so far as they succeed in simultaneously producing products and the need for those products through practices which are the denial of the ordinary practices of the 'economy' the struggles which take place within them are ultimate conflicts involving the whole relation to the 'economy'. ${ }^{71}$

Perspektif ini menunjukkan, bahwa dominasi Taman Budaya dalam mengimposisi wacana dan praktik kesenian di Provinsi Jambi, tidak terlepas dari counter kolega dan kritikus yang mengevaluasi skema kerja Taman Budaya dalam menjalankan proses preservasi. Munculnya fraksi-fraksi yang mengkritisi kerja-kerja Taman Budaya merupakan ketidak-puasan terhadap mekanisme dan orientasi lembaga yang bergerak di bidang kesenian tersebut.

Seperti yang diungkapkan Jefri: "belakangan ini Taman Budaya sudah tidak selektif dalam memilih material kesenian dan kreator, hanya terkesan merekonstruksi dan merevitalisasi kesenian yang dianggap tidak berkembang atau punah tanpa memikirkan proses jangka panjang guna dilestarikan". 72

Pada sisi lain, Ari Cekgu mengungkapkan bahwa:

\footnotetext{
${ }^{71}$ Dalam, Pierre Bourdieu..., 1993. 82.

72 Jefri. Staf di Dinas Pariwisata Provinsi Jambi. Wawancara tanggal 24 Februari, di Taman Budaya Jambi.
} 
"saat melakukan penilaian dan pemilihan objek untuk diteliti, dieksplorasi, dan dipertontonkan, Taman Budaya tidak pernah berkolaborasi dengan 'tenaga ahli', baik yang independen maupun dengan lembaga lain diluar Taman Budaya, putarannya pasti itu-itu juga". 73

Persepsi ini merupakan evaluasi atas kerja Taman Budaya dan mengisyaratkan suatu krisis kepercayaan tentang bagaimana relasi kuasa melakukan ekspektasi terhadap ide-ide yang mesti dijalankan, tanpa mempertimbangkan mekanisme keberlanjutan. Di sini terlihat, bahwa dominasi Taman Budaya sangat kuat dalam mengimposisi struktur arena karya seni, imbasnya pada legitimasi produsen dan produk yang dikonsekrasi tertuju pada selera berdasarkan relasi kuasa. Perihal ini berkesuaian dengan apa yang dikatakan Bourdieu, bahwa the field of cultural production is the site of struggles in which what is at stake is the power to impose the dominant definition of the writer and therefore to delimit the population of those entitled to take part in the struggle to define the writer. ${ }^{74}$

$$
\text { Praktik artistic yang }
$$
dilegitimasi Taman Budaya sebagai

73 Ari Cekgu. Pemerhati Budaya dan Anggota Dewan Kesenian Jambi. Wawancara tanggal 3 Maret.

${ }^{74}$ Pierre Bourdieu..., 1993. 42. salah satu kesenian yang berangkat dari tradisi masyarakat Jambi, merupakan wujud konkrit dari dominasi kuasa Taman Budaya dalam mengimposisi dan memproduksi model seni dengan mengusung tema tradisi sebagai dasar tindakan menuju pelestarian inovatif. ${ }^{75}$ Perihal tersebut perlu diapresiasi, namun, mekanisme dari wujud pelestarian menuntut adanya kesinambungan yang kontinu.

Realitas aktual karya seni yang dipercaya memiliki modal kultural ketika dijadikan pilihan untuk diaktualisasikan kepada publik, dan sebagai disposisi estetik di dalam arena pertarungan karya seni skala luas, "saat ini sudah tidak pernah lagi dibicarakan, sebab tidak jelas langkah-langkah Taman Budaya untuk melakukan proses pelestarian". 76 "Pada akhirnya, asumsi negatif muncul terhadap semua aktivitas kerja yang dilakukan Taman Budaya, bahwa kegiatan-kegiatan yang diprogramkan hanya bagian dari

75 Ja'far Rasuh, "Begandai Batok, Upaya Revitalisasi Musik Gandai Yang Sudah Lenyap". (Koran Lokal: Jambi Independent, 18 Juni).

76 Jefri. Staf di Dinas Pariwisata Provinsi Jambi. Wawancara tanggal 24 Februari, di Taman Budaya Jambi. 
'proyek' pelepasan anggaran pendapatan". 77

Dari sini, mengikuti pendapat Lono Simatupang bahwa seharusnya peran-peran yang dapat dimainkan pemerintah dalam pengembangan kebudayaan dan kesenian memerlukan kebijakan yang tepat dan jelas, bahwa kebijakan kebudayaan tidak terbatas pada tugas dan wewenang instansi tertentu, misalnya Dinas Pariwisata, Seni dan Budaya. Kebudayaan seyogyanya diletakkan sebagai perspektif -bukan program, apalagi proyek- dan diterapkan pada semua sektor pemerintahan sehingga pelaksanaan peran-peran pemerintah dalam pengembangan kebudayaan dan kesenian seyogianya bersifat lintas sektoral. Sifat lintas sektoral tersebut tidak hanya berlaku pada tataran konsolidasi program, namun juga dalam pendanaan dan pelaksanaan. ${ }^{78}$

\section{KEPUSTAKAAN}

Ahimsa-Putra, H. Sri. Strukturalisme Levi-Strauss: Mitos dan Karya Sastra. Yogyakarta, Kepel Press, 2006.

Anderson, Benedict. Imagined Communities. Terj. Omi Intan

77 Ari Cekgu. Pemerhati Budaya dan Anggota Dewan Kesenian Jambi. Wawancara tanggal 3 Maret.

${ }^{78}$ Lono Simatupang..., 2013. 277
Naomi. Yogyakarta, Insist Press, 2001.

Barker, Chris. Cultural Studies: Teori dan Praktik. Terj. Nurhadi. Yogyakarta: Kreasi Wacana, 2004.

Bourdieu, Pierre. Outline of a Theory of Practice. Trans. by Richard Nice. Cambridge University Press, 1977.

Distinction. A Sosial Critique of Judgement of Taste. Diterjemahkan dalam bahasa Inggris oleh Richard Nice. Cambridge, Massachusetts, Harvard University Press, 1984. In Other Words: Essay Toward a Reflexive Sociologi. California, Standford University Press, 1990.

The Field of Cultural Production: Essays on Art and Literature. Ed. and Introduction Randal Johnson. New York, Columbia University Press, 1993.

Choses Dites: Uraian dan Pemikiran. Terj. Ninik Rochani Sjams. Yogyakarta, Kreasi Wacana, 2011.

Featherstones, Mike. Posmodernisme dan Budaya Konsumen. Terj. Misbah Zulfa Elizabeth. Yogyakarta, Pustaka pelajar, 2008.

Field, John. Social Capital. London: Routledge, Taylor \& Francis Group, 2008.

Foucault, Michel. The Order of Thing; An Archeology of the Human Science. New York, Phanheon Book, 1970.

Gunawan, Jamil. Dkk. Ed. Desentralisasi Globalisasi dan Demokrasi Lokal. Jakarta, LP3ES, 2005.

Harker, Richard. Dkk. ed. (Habitus $x$ Modal $)+$ Ranah $=$ Praktik . 
Terj. Pipit Maizier. Yogyakarta, Jalasutra, 2009.

Haryatmoko. "Seni, Kreativitas, dan

Deteritorialisasi". Prosiding

Seminar Nasional Festival

Kesenian Indonesia Ke-8.

Yogyakarta, BP ISI Yogyakarta, 2014.

Henk Schulte Nordholt dan Gerry van

Klinken. Politik Lokal di

Indonesia. Leiden, KITLV

Press, 2007.

Holt, Claire. Melacak Jejak

Perkembangan Seni di

Indonesia. Terjemahan. R.M.

Soedarsono. Bandung, MSPI, 2000.

Jacob, T. "Manusia Melayu Kuno", dalam kumpulan tulisan, Seminar Sejarah Melayu Kuno; Jambi, 7-8 Desembar 1992. Pemda Tk. I. Jambi, 1992.

Laclau, Ernesto dan Mauffe, Chantal. Hegemoni dan strtegi sosialis. Terj. Eko Prasetyo Darmawan. Yogyakarta, Resist Book, 2008.

Marsden, William. Sejarah Sumatra. Terjemahan. Komunitas Bambu. Depok, Komunitas Bambu, 2013 [1811].

Mubyarto. dkk. Sistem Infrastruktur Pedesaan di Provinsi Jambi. Yogyakarta, P3PK UGM, 1990.

Ritzer, George, dan Goodman, Douglas J. Teori Sosiologi. Terj. Nurhadi. Yogyakarta, Kreasi Wacana, 2008.

Simatupang, Lono. Pergelaran. Yogyakarta, Jalasutra, 2013.

Sutrisno, Mudji. ed. Hermeneutika Pascakolonial. Yogyakarta, Kanisius, 2004.

Svasek, Maruska. Anthropology, Art and Cultural Production. London, Pluto Press, 2007.

Thompson, John B. Kritik Ideologi Global. Terj. Haqqul Yaqin. Yogyakarta, IRCiSoD, 2004. 